\title{
Noradrenaline plays a critical role in the switch to a manic episode and treatment of a depressive episode
}

This article was published in the following Dove Press journal:

Neuropsychiatric Disease and Treatment

20 September 2016

Number of times this article has been viewed

\begin{abstract}
Masatake Kurita ${ }^{1-3}$
'Koutokukai Wakamiya Hospital, Yoshihara, Yamagata, ${ }^{2}$ Department of Cellular Signaling, Graduate School of Pharmaceutical Sciences, Tohoku University, Sendai, ${ }^{3}$ Department of Psychiatry and Behavioral Science, Graduate School of Medicine, Nippon Medical School, Tokyo, Japan
\end{abstract}

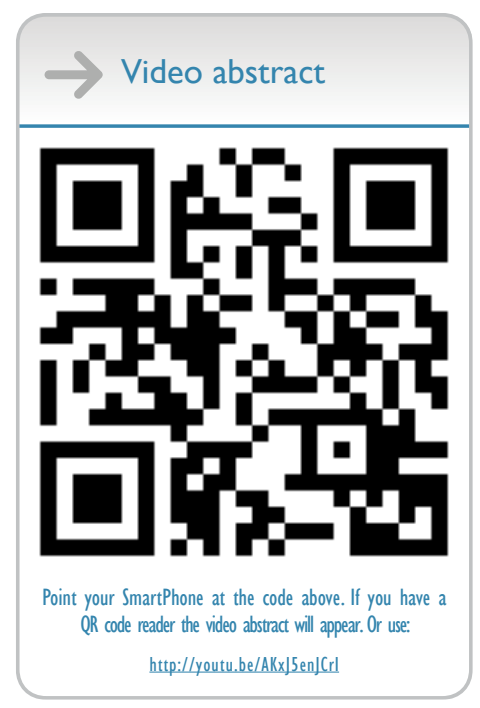

Correspondence: Masatake Kurita Koutokukai Wakamiya Hospital, 2-I5-3 Yoshihara, Yamagata 990-245I, Japan

Tel +8I 236438222

Email kurita@koutoku.or.jp
Abstract: Although antidepressants may increase the risk of switching to mania in bipolar disorder (BD), clinicians have been using antidepressants to treat patients with bipolar depression. Appropriate treatments for bipolar depression remain controversial. In BD, antidepressants comprise a double-edged sword in terms of their efficacy in treating depression and the increased risk of switching. This review presents an important table outlining the benefit in terms of depression improvement and the risk of switching in the clinical setting. It also proposes strategies based on the characteristics of antidepressants such as their pharmacology, specifically the equilibrium dissociation constant $\left(K_{\mathrm{D}}\right)$ of the noradrenaline transporter. This table will be useful for clinicians while considering benefit and risk. Antidepressants augmenting noradrenaline may be effective in bipolar depression. However, it is easily presumed that such antidepressants may also have a risk of switching to mania. Therefore, antidepressants augmenting noradrenaline will be the recommended treatment in combination with an antimanic agent, or they may be used for short-term treatment and early discontinuation. The corresponding medical treatment guidelines probably need to be reevaluated and updated based on biological backgrounds. From previous studies, we understand that the stability of noradrenaline levels is important for BD amelioration, based on the pathophysiology of the disorder. It is hoped that researchers will reevaluate $\mathrm{BD}$ by conducting studies involving noradrenaline.

Keywords: 3-methoxy-4-hydroxyphenylglycol, dopamine, homovanillic acid, brain-derived neurotrophic factor, biomarker, antidepressants, selective serotonin reuptake inhibitor, serotonin and noradrenaline reuptake inhibitor, tricyclic antidepressant, mood disorder

\section{Bipolar disorder}

Bipolar disorder (BD) is an episodic illness characterized by recurrent manic, mixed, and depressive episodes, with an estimated global lifetime prevalence of $1 \%-5 \% .{ }^{1} \mathrm{BD}$ is defined in the diagnostic criteria of the International Classification of Diseases (ICD, World Health Organization, 2010) $)^{2}$ and the Diagnostic and Statistical Manual of Mental Disorders (DSM, American Psychiatric Association, 2013) ${ }^{3}$ as being different from major depressive disorder, schizophrenia, and other psychiatric disorders. The illness is associated with high levels of mortality and morbidity, ${ }^{4}$ functional impairment, ${ }^{5}$ and high rates of suicide. ${ }^{6}$ Despite the fact that the switching is a core aspect of the clinical presentation of BD, the biological background of the pathology is still poorly understood.

In particular, the longitudinal symptomatic course of BD is chronic and dominated by depressive symptoms, rather than the characteristic manic symptoms of BD, and surprisingly - the depressive state can be dominant for as much as $\geq 50 \%$ during the course of BD. ${ }^{7-9}$ These longitudinal depressive symptoms lead to loss of social benefits 
for BD patients. On the other hand, when it comes to switching to mania, patients with BD lose many aspects of their lives and experience problems such as debts and divorce. $\mathrm{BD}$ patients in the mixed ${ }^{10}$ or depressive ${ }^{11}$ states are more prone to suicide.

\section{Treatment for bipolar disorder}

Even though many reports and guidelines have suggested that antidepressants may increase the risk of switching to mania in $\mathrm{BD},{ }^{12,13}$ clinicians have been using antidepressants to treat patients with bipolar depression. ${ }^{14,15}$ While this may sound strange to researchers of pharmacology, it is not unusual in the clinical field. Although antidepressants are used to treat bipolar depression currently, the specific mechanisms that are modified by antidepressants and cause the switching to mania remain unclear.

Early improvement of patients with BD during their long-term depressive symptom is beneficial to the outcome of the treatment for this disorder, but this has been a great challenge to - as well as the aim of - clinicians, who, when treating the patient, is struggling with a dilemma of having to choose between improvement of the depressive symptom and switching to mania. Therefore, clinicians need to understand the characteristics of antidepressants for their optimal use for improvement and offset the risk of switching to mania. Furthermore, researchers need to understand the pathophysiology of BD to facilitate their work on drugs that help in symptom improvement and overcome the risk of switching to mania.

Currently, the clinical guidelines ${ }^{6,16}$ grade the risk of switching to mania by classifying antidepressants into groups such as selective serotonin reuptake inhibitors (SSRIs), serotonin and noradrenaline reuptake inhibitors (SNRIs), and tricyclic antidepressants (TCAs). Even though these agents have similar pharmacological effects as the monoamine reuptake inhibitor, the pharmacological characteristics are different for each medication even within the same class.

To begin with, this review summarizes the clinical evidence with particular focus on the biological characteristics underpinning the pathophysiology of BD in the section on "Biological background". Next, this review outlines the treatment guidelines and formulates a strategy with particular focus on bipolar depression.

Overall, the proportion of patients receiving at least one mood stabilizer increases significantly every year. ${ }^{17}$ The significant increases in the prescription of mood stabilizers probably reflect the increasing awareness and implementation of recent evidence-based medicine guidelines into clinical practice. $^{16}$
Regarding treatment with antidepressants, some studies and treatment guidelines suggest that antidepressant treatments for BD may have the potential to increase manic switching, while others recommend short-term antidepressant treatment and early discontinuation. ${ }^{12,13}$ Nevertheless, even now, clinicians have been using antidepressants to treat BD patients with acute bipolar depression. The possible disadvantages of longitudinal depression may be greater for BD patients than the disadvantages of switching to mania, as a matter of course, clinicians should avoid the treatment of BD patients with medicines that increase the risk of switching to mania. Regarding treatment with antidepressants for bipolar depression, antidepressants were not found to be statistically superior to placebo or other current standard treatments for bipolar depression. ${ }^{18,19}$ However, it is also reported that antidepressants were more effective than placebo. ${ }^{15}$ Antidepressants were also reported to be effective for the shortterm treatment of bipolar depression. ${ }^{15}$ More interestingly, a previous study suggested that switching is a common early complication of treatment with antidepressants. ${ }^{18}$ Thus, the risk of switching to mania differed widely according to the types of antidepressants. The rate of switching for TCAs was $10 \%$, while that for all other antidepressants combined was $3.2 \%{ }^{15}$ These findings show that the rates of switching differ within the same class of antidepressants. Thus, I suggest that the rate of switching is decided by the pharmacologic strength and dose of a particular drug, rather than by a simple common pharmacological action.

Based on these differences in the risk of switching, avoiding the use of TCAs has generally been proposed in clinical reports. ${ }^{12,13}$ Clinicians would have had suspicions that antidepressants other than TCAs are superior in terms of both the risk of switching and the efficacy against depression compared with TCAs. Furthermore, these studies do not provide evidence that all antidepressants in the same class can provide equally beneficial results in terms of similar pharmacological effects on BD patients. Antidepressants may be a double-edged sword. Clinicians should carefully consider both the risk of switching and the efficacy against depression from the point of view of pharmacology for each medication, rather than looking for similar pharmacological effects.

Considering these discussions, the pathology of BD needs to be verified. Thus, it should be acknowledged that BD can be influenced by certain types of substances. Although BD patients experience spontaneous switching, this can also be induced by antidepressants. Therefore, it is necessary to know about the existence of substances affecting the biological background during the process of switching to mania. In the 
next part of the review, the first paragraph describes my understanding of the biological background of $\mathrm{BD}$ to date.

\section{Biological background Spontaneous hypothesis}

Retrospective data obtained from patients hospitalized between 1920 and 1959 revealed a rate of $29 \%$ for spontaneous switching from depression to hypomania. ${ }^{20}$ The fact that most patients with BD receive mood stabilizers makes spontaneous switching even more difficult to estimate accurately. ${ }^{15}$ In studies on genetic polymorphisms associated with responses to antidepressants, spontaneous switching was proposed to have a very different mechanism from that associated with responses to antidepressants. ${ }^{21}$ Thus, although the possibility of spontaneous switching cannot be denied, many reports have suggested that a past history of multiple antidepressant trials is associated with switching to mania. ${ }^{22}$ It is reasonable to think that some substances that assist antidepressants in switching to mania do exist.

\section{Catecholaminergic hypothesis}

Higher levels of urinary noradrenaline ${ }^{23-25}$ and dopamine ${ }^{24,25}$ have been associated with mania and switching to mania. In a double-blind, randomized, placebo-controlled study on bipolar depression, almost all subjects treated with L-3,4dihydroxyphenylalanine (L-dopa), the catecholamine precursor, developed hypomanic symptoms after $\sim 1$ week. ${ }^{26}$ More interestingly, the incidence of hypomania was increased with a greater dose of L-dopa, and a reduction in dose or discontinuation of L-dopa was followed by disappearance of the hypomanic symptoms within 48 hours in these patients. ${ }^{26}$ Thus, in bipolar patients, hypomanic behaviors are induced more than spontaneous mania by L-dopa, and catecholamines are involved in the pathophysiology of BD. However, patients with major depressive disorder were not induced toward hypomanic symptoms when treated with L-dopa. These findings may indicate that the pathophysiology based on biological substances differs between bipolar depression and major depression. Moreover, on L-dopa administration at similar dosages to 394 patients with Parkinson's disease, hypomania was described in only three patients $(<1 \%) .{ }^{26}$ Meanwhile, schizophrenia-like symptoms, such as organic hallucinosis, develop as the most common drug-induced side effects of L-dopa. ${ }^{27}$ The increase in monoamine levels induced by L-dopa involves two substances. One is dopamine, and the other is noradrenaline. Although the switching process is correlated with monoamines, the roles of the noradrenergic and dopaminergic systems in the switching process are not clearly defined. It is easy to imagine that schizophrenia and dopamine have a strong correlation. Although mania has partially similar symptoms as schizophrenia, it is not the same disorder as a whole, and it is important to note that $\mathrm{BD}$ has different symptoms from schizophrenia. It is clinically important to understand that manic symptoms are different from schizophrenia-like symptoms according to the ICD and DSM.

On the other hand, in clinical studies on 3-methoxy-4hydroxyphenylglycol (MHPG), noradrenaline metabolites, and homovanillic acid (HVA), the dopamine metabolite levels were higher in bipolar manic patients than in bipolar remission patients on antipsychotics (chlorpromazine equivalence: $380 \pm 110$ and $300-600 \mathrm{mg} / \mathrm{d}$, respectively). ${ }^{28-30}$ Thus, it is known that levels of dopamine, noradrenaline metabolites, HVA, and MHPG are reduced by antipsychotic drug treatment. Unfortunately, it is not clear whether the depletion of HVA or MHPG is caused by the antipsychotics or improvement in symptoms. It is important for researchers to understand that depression is a different symptom from sedation induced by antipsychotics. Likewise, the roles of the noradrenergic and dopaminergic systems in the switching process from mania to depression are not clearly defined.

\section{Dopaminergic hypothesis}

Amphetamine has been shown to trigger euphoria in healthy volunteers, mostly through increased dopamine levels in the anteroventral striatum. ${ }^{31}$ In addition, Lu et al ${ }^{32}$ indicated a possible relationship between manic symptoms and ketamine abuse in a case report. This relationship may be attributed to the increased dopamine level in the brain tissue brought about through dopamine release after chronic dosing with ketamine. ${ }^{33}$ Thus, pharmacological evidence supports the notion that manipulation of the dopaminergic system can mimic the symptoms of BD. However, amphetamine- or ketamine-induced psychotic disorder and the manic state of BD differ in the diagnostic criteria of the ICD and DSM. Thus, some of these similar symptoms cause confusion in devising pharmacological strategies. However, the use of aripiprazole, a partial agonist of the dopamine D2 receptor, ${ }^{34}$ during the maintenance phase was reported to protect against manic relapses, but not against depressive relapses. ${ }^{35,36}$ Furthermore, this drug was shown to be negative in treating bipolar depression. ${ }^{37}$ From these clinical findings, it may be surmised that dopamine may be involved in sedation or calmness, but not in the pathophysiology of BD.

\section{Noradrenergic hypothesis}

The urinary concentrations of noradrenaline and its metabolite MHPG were significantly lower in depression than in 


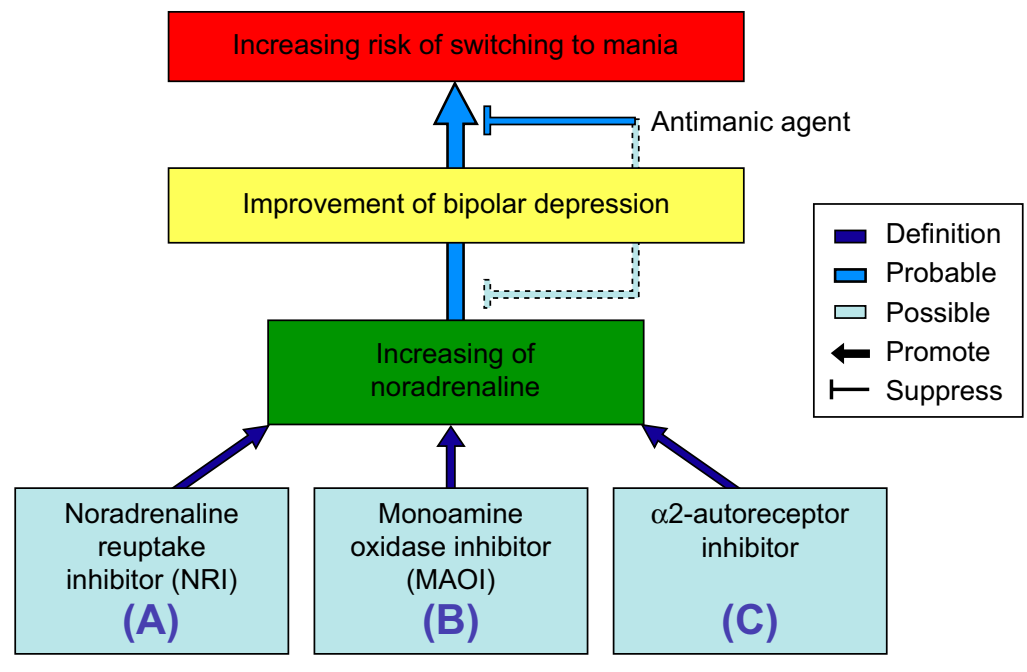

Figure I Schematic illustration showing the improvement or switching pathways induced by various antidepressants affecting the levels of noradrenaline. Notes: Augmentation of noradrenaline as various antidepressants can be the result of the three actions: $(\mathbf{A})$ noradrenaline reuptake inhibitory action, $(\mathbf{B})$ inhibitory action of noradrenaline deactivation, and (C) $\alpha 2$-autoreceptor inhibitory action.

mania. ${ }^{23}$ Although HVA, a dopamine metabolite, did not differ, MHPG, a noradrenaline metabolite, was greater in untreated BD patients than in healthy controls. ${ }^{38}$ Recently, it was reported that MHPG is a biomarker for the switch from the manic state to the remission state in $\mathrm{BD} .{ }^{28}$ The study suggested that the effects of antipsychotics were slight with reference to chlorpromazine equivalence (average: $134 \mathrm{mg} / \mathrm{d}$ ). In addition, in multiple regression analyses, the plasma levels of MHPG reflected the pathophysiology of BD from the manic state to the depressive state more clearly than did plasma HVA or brain-derived neurotrophic factor (BDNF). ${ }^{9}$ Thus, noradrenaline may be involved in the pathophysiology of BD (Figure 1).

\section{BDNFergic hypothesis}

Blood BDNF levels in the manic state were reported to be high $^{39,40}$ or low ${ }^{41}$ in different studies, compared with remission or control subjects, and the conclusions were incoherent and unclear. In our study, BD patients exhibited no significant changes in BDNF level throughout the manic state. ${ }^{28}$ In the human brain, BDNF immunoreactivity was reported to be increased in postmortem hippocampal tissues obtained from subjects with major depression, BD, or schizophrenia, as well as in nonpsychiatric control subjects treated with antidepressant medications. ${ }^{42}$ In contrast, chronic (21 days) treatment with the TCA desipramine, the SSRI fluoxetine, and the monoamine oxidase inhibitor (MAOI) phenelzine increased BDNF levels in the frontal cortex. ${ }^{43}$ Interestingly, the increases in BDNF showed differences and were in the following order: $\mathrm{MAOI}>\mathrm{SSRI}>\mathrm{TCA}>$ vehicle. If BDNF is involved in the switching to mania, explanation of this observation becomes very difficult. In addition, BDNF was not correlated with the manic state of BD in our study. ${ }^{28}$ Furthermore, BDNF did not show correlations among the depressive, remission, and manic states of BD in another report. ${ }^{9}$

\section{Noradrenaline and antidepressants}

From these hypotheses, it is supported that noradrenaline is involved in the pathophysiology of BD, as well as being associated with the switch to mania. In this context, it is suggested that both the antidepressant effect of and the switching to mania caused by noradrenaline are issues of particular importance in the context of BD. Augmentation of noradrenaline can be the result of the following three actions (Figures 1 and 2): (A) increasing noradrenaline in the synaptic cleft by noradrenaline reuptake inhibitory action; (B) inhibition of noradrenaline deactivation by MAOIs; and (C) release of noradrenaline by $\alpha 2$-autoreceptor blockage. The following three sources underlie this evidence. For (A), antidepressants are involved with noradrenaline reuptake transporter (NRT), and noradrenaline reuptake inhibitors (NRIs) were more effective than placebo for bipolar depression. ${ }^{15}$ In addition, avoiding antidepressant use has generally been proposed in clinical guidelines, considering the potential risk for switching to mania or rapid cycling during the treatment. ${ }^{16,44}$ Thus, NRT may participate in the pathophysiology of BD. For (B), the development of an ${ }^{11} \mathrm{C}$-harmine brain-imaging technique led to the interesting observation that brain monoamine oxidase (MAO) levels were elevated in a number of cortical, striatal, and midbrain areas in subjects suffering from major depressive disorder. ${ }^{45}$ However, even after the complete characterization of MAO-A and MAO-B subtypes, 


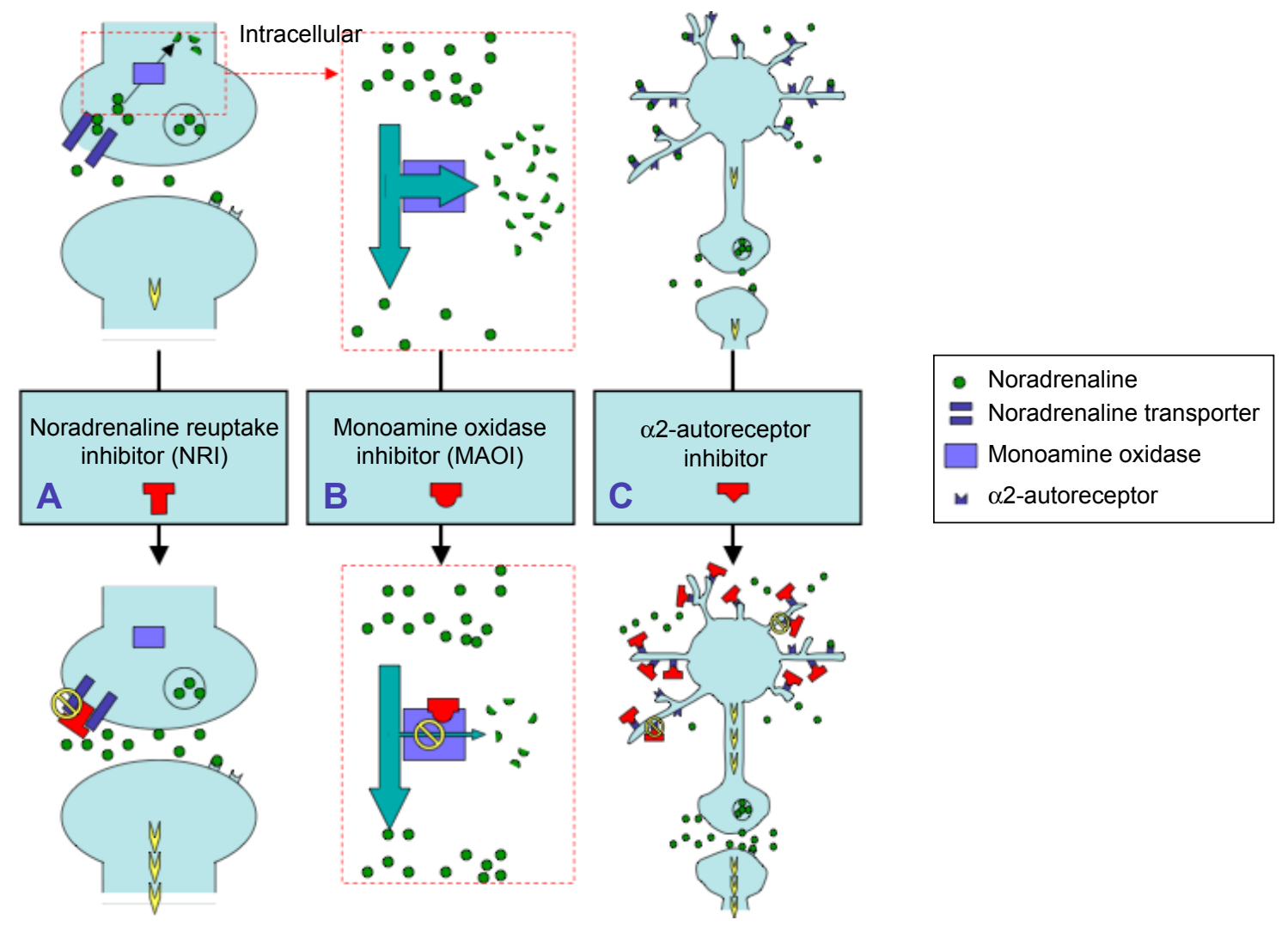

Figure 2 Schematic illustration of the pathways leading to increasing noradrenaline levels as caused by the administration of various antidepressants.

Notes: (A) Administration of a NRI increases the levels of noradrenaline at the synapse, resulting in activation of intracellular signal transduction cascades that are coupled with noradrenergic receptors. (B) Monoamine oxidase is deactivated by oxidative deamination of noradrenaline. Administration of a MAOI suppresses the levels of noradrenaline deactivation, resulting in increased levels of noradrenaline at the synapse. (C) Activated $\alpha 2$-autoreceptor inhibits the release of noradrenaline. Administration of an $\alpha 2$-autoreceptor inhibitor can promote noradrenaline release via suppression of this autoreceptor.

Abbreviations: MAOI, monoamine oxidase inhibitor; NRI, noradrenaline reuptake inhibitor.

many aspects of the physiological actions of these enzymes are unclear. ${ }^{46} \mathrm{MAO}$ is localized intracellularly. ${ }^{47}$ Thus, in the cell, pathway (B) works through pathway (A). From the pharmacological point of view, pathway (A) takes precedence over pathway (B) in the mechanism of switching to mania (Figure 2). For (C), mirtazapine is an antidepressant that blocks the $\alpha 2$-autoreceptor. It was shown in a case report that mirtazapine induced switching to a manic state. ${ }^{48}$ In contrast, another report showed that this medicine did not induce switching to a manic state. ${ }^{49}$ Large-scale follow-up studies are needed to understand the effects of mirtazapine.

For these reasons, the impact of the switch to mania and the antidepressive effect of NRT in bipolar depression are discussed in the context of pathway (A) in this review.

\section{Antidepressants and bipolar depression}

Classification of antidepressants as TCAs or SSRIs is confusing for clinicians. For a focus on NRIs, it might be necessary to verify both the manic risk and antidepressive effect for each medication. In the treatment of bipolar depression, a pharmaceutical class effect is the exception rather than the rule, and such class effects only involve the switching to mania and the drug class of antidepressants. Thus, the effect of the individual drug is more important than the drug class.

It is interesting to note that two naturalistic studies found significantly lower rates of switching to mania when patients were treated with SSRIs compared with those on TCAs. ${ }^{50,51}$

As can be seen from the values of the equilibrium dissociation constant $\left(K_{\mathrm{D}}\right)$ for noradrenaline transporter (NET), TCAs are substantially more potent with reference to noradrenaline reuptake action in comparison with all SSRIs. In this review, it was reported that a potent positive correlation between the mania rating scale and noradrenaline metabolite levels are correlated in two reports. Therefore, it is suggested that the strength of noradrenaline reuptake action, based on the $K_{\mathrm{D}}$ value of NET, indicates a potent risk factor for switching to mania when BD patients are treated with antidepressants. The relative risk factors of 
Table I Various antidepressants showing the improvement of depression or the risk of switching to mania based on their affinities for NET

\begin{tabular}{|c|c|c|c|c|}
\hline \multirow[t]{2}{*}{ Antidepressants } & \multirow{2}{*}{$\frac{K_{\mathrm{D}}, \mathrm{nM} *}{\mathrm{NET}}$} & \multirow{2}{*}{$\frac{\text { Dose }}{\text { Min-Max }}$} & \multirow{2}{*}{$\frac{\text { Dose/K }}{\text { Min-Max }}$} & \multirow{2}{*}{$\frac{\text { Dose risk }}{\text { Min-Max }}$} \\
\hline & & & & \\
\hline \multicolumn{5}{|l|}{ Tertiary amine tricyclics } \\
\hline Amitriptyline & 35.0 & $50-300$ & $1.43-8.57$ & $(++)-(++)$ \\
\hline Clomipramine & 38.0 & $25-200$ & $0.66-5.26$ & $(-)-(++)$ \\
\hline Dosulepin & 46.0 & $25-125$ & $0.54-2.72$ & $(-)-(+)$ \\
\hline Imipramine & 29.5 & $75-300$ & $2.54-10.17$ & $(+)-(+++)$ \\
\hline Doxepin & 37.0 & $150-300$ & $4.05-8.11$ & $(++)-(++)$ \\
\hline Lofepramine & 5.4 & $25-300$ & $4.63-55.56$ & $(++)-(+++)$ \\
\hline Trimipramine & $2,450.0$ & $50-150$ & $0.02-0.06$ & $(-)-(-)$ \\
\hline \multicolumn{5}{|l|}{ Secondary amine tricyclics } \\
\hline Amoxapine & 16.1 & $100-400$ & $6.21-24.84$ & $(++)-(+++)$ \\
\hline Desipramine & 0.8 & $75-300$ & $93.75-375.00$ & $(+++)-(+++)$ \\
\hline Desmethylclomipramine & 2.5 & $10-25$ & $4.00-10.00$ & $(++)-(+++)$ \\
\hline Nortriptyline & 4.4 & $50-150$ & $11.36-34.09$ & $(+++)-(+++)$ \\
\hline Protriptyline & 1.4 & $15-40$ & $|0.7|-28.57$ & $(+++)-(+++)$ \\
\hline \multicolumn{5}{|l|}{ Tetracyclics } \\
\hline Maprotiline & 11.1 & $50-150$ & $4.50-|3.5|$ & $(+++)-(+++)$ \\
\hline Mianserin & 71.0 & $30-90$ & $0.42-1.27$ & $(-)-(+)$ \\
\hline \multicolumn{5}{|l|}{ SARI } \\
\hline Trazodone & $8,500.0$ & $25-400$ & $0.00-0.05$ & $(-)-(-)$ \\
\hline \multicolumn{5}{|l|}{ SSRIs } \\
\hline Citalopram & $4,070.0$ & $20-80$ & $0.00-0.02$ & $(-)-(-)$ \\
\hline Fluoxetine & 240.0 & $10-60$ & $0.04-0.25$ & $(-)-(-)$ \\
\hline Fluvoxamine & $1,300.0$ & $100-300$ & $0.08-0.23$ & $(-)-(-)$ \\
\hline Paroxetine & 40.0 & $20-50$ & $0.50-1.25$ & $(-)-(+)$ \\
\hline Sertraline & 420.0 & $25-200$ & $0.06-0.48$ & $(-)-(-)$ \\
\hline \multicolumn{5}{|l|}{ SNRIs } \\
\hline Nefazodone & 360.0 & $100-600$ & $0.28-1.67$ & $(-)-(+)$ \\
\hline Venlafaxine & $1,060.0$ & $150-225$ & $0.14-0.21$ & $(-)-(-)$ \\
\hline
\end{tabular}

Notes: $K_{D}$ is the equilibrium dissociation constant. -, no possibility; +, possibility $(>1)$; ++, strong possibility $(>3)$; ++, very strong possibility $(>10)$. *Reprinted from Eur $J$ Pharmacol, Tatsumi M, Groshan K, Blakely RD, Richelson E, Pharmacological profile of antidepressants and related compounds at human monoamine transporters, 249-258, ${ }^{52}$ Copyright (1997), with permission from Elsevier. http://www.sciencedirect.com/science/journal/00142999.

Abbreviations: max, maximum; min, minimum; NET, noradrenaline transporter; SARI, serotonin-2 antagonist/reuptake inhibitor; SNRI, serotonin and noradrenaline reuptake inhibitor; SSRI, selective serotonin reuptake inhibitor.

various antidepressant drugs using the $K_{\mathrm{D}}$ values of $\mathrm{NET}^{52}$ for switching to mania are shown in Table 1.

These risk factors for switching to mania were determined based on this simple premise and are indicated as no possibility (-), possibility (+), strong possibility $(++)$, or very strong possibility $(+++)$. It is suggested that high- $K_{\mathrm{D}}$ NET drugs should be recommended more often relative to very low- $K_{\mathrm{D}}$ NET drugs such as secondary amine TCAs. Additionally, antidepressants should be carefully considered in terms of the balance between the risk of switching and the efficacy against depression before recommending low- $K_{\mathrm{D}}$ NET drugs for bipolar depression. Further studies with larger naturalistic study populations may be necessary to confirm the benefits of NET $K_{\mathrm{D}}$ information in the treatment of bipolar depression.

Interestingly, the effects of antidepressants are different from the effects of noradrenaline, even if the classifications are the same. The data do not suggest that switching is a common early complication of treatment with antidepressants. It is suggested that both the risk of switching and the efficacy against depression should be evaluated for each medication, rather than by similar pharmacological effects. A recent double-blind, placebo-controlled study evaluating paroxetine monotherapy in the treatment of bipolar depression failed to show any advantage compared with placebo. ${ }^{53}$ This finding for paroxetine is consistent with those in Table 1.

Augmentation of noradrenaline is effective for treating the depressive state in $\mathrm{BD}$ but entails the risk of switching to mania in BD. Therefore, if the depressive symptom is severe, the short-term treatment to augment noradrenaline will be recommended for severe bipolar depression. However, if the depressive symptom is mild or in remission, augmentation of noradrenaline will increase the risk of switching to mania. Consequently, NRIs will not be recommended for maintenance treatment. Thus, antidepressants with strong 
indications should be used in the short-term treatment for severe bipolar depression.

\section{Conclusion}

In summary, the results for plasma levels of MHPG may reflect the pathophysiology of $\mathrm{BD}$ from the manic state to the depressive state more than the plasma levels of HVA or BDNF. These data suggest that peripheral MHPG, which is associated with noradrenaline levels in the brain, could be used as a biomarker for whole mood states in BD. The MHPG levels, reflecting the noradrenaline levels in the brain, are likely to reflect the clinical characteristics of the switching process in $\mathrm{BD}$ and to have prognostic significance for the treatment of manic and depressive states. Therefore, it is suggested that antidepressant treatment for BD should be considered on the basis of the $K_{\mathrm{D}}$ values for NET. Antidepressants may be effective for the short-term treatment of bipolar depression. In addition, clinicians should carefully consider treatment strategies based on the biological background. From our study, the augmentation of noradrenaline will have beneficial effects in bipolar depression, while being associated with an increased risk of switching in BD. Thus, augmentation of noradrenaline is a double-edged sword. Consequently, antidepressants may need to be used in combination with an antimanic agent, such as lithium, as suggested in the guidelines. It is hoped that agents such as noradrenaline stabilizers are developed for $\mathrm{BD}$ in the future. Antidepressants augmenting noradrenaline may be effective for bipolar depression. However, it is easily presumed that such antidepressants will also have a risk of switching to mania. Therefore, antidepressants will be the recommended treatment in combination with an antimanic agent, or for short-term treatment with early discontinuation, as suggested in other reports. Guidelines for medicinal treatment should probably be reevaluated and updated based on the biological background.

\section{Acknowledgments}

The publication fees for this review were supported by funding from the Sato Hospital, Koutokukai, Japan. The review did not receive funding from any pharmaceutical corporations.

\section{Disclosure}

The author reports no conflicts of interest in this work.

\section{References}

1. Kastrup MC, Ramos AB. Global mental health. Dan Med Bull. 2007; 54(1):42-43.

2. World Health Organization, International Classification of Diseases. 10th revision. Geneva, Switzerland: World Health Organization; 2010.
3. American Psychiatric Association. Diagnostic and Statistical Manual of Mental Disorders. 5th ed. Washington, DC: American Psychiatric Association; 2013.

4. Rush AJ. Toward an understanding of bipolar disorder and its origin. J Clin Psychiatry. 2003;64(suppl 6):4-8. [discussion 28].

5. Rosa AR, Franco C, Martinez-Aran A, et al. Functional impairment in patients with remitted bipolar disorder. Psychother Psychosom. 2008; 77(6):390-392.

6. Association AP. Practice guideline for the treatment of patients with bipolar disorder (revision). Am J Psychiatry. 2002;159(4 suppl):1-50.

7. Judd LL, Akiskal HS, Schettler PJ, et al. The long-term natural history of the weekly symptomatic status of bipolar I disorder. Arch Gen Psychiatry. 2002;59(6):530-537.

8. Judd LL, Akiskal HS, Schettler PJ, et al. A prospective investigation of the natural history of the long-term weekly symptomatic status of bipolar II disorder. Arch Gen Psychiatry. 2003;60(3):261-269.

9. Kurita M, Nishino S, Numata Y, Okubo Y, Sato T. The noradrenaline metabolite MHPG is a candidate biomarker between the depressive, remission, and manic states in bipolar disorder I: two long-term naturalistic case reports. Neuropsychiatr Dis Treat. 2015;11:353-358.

10. Young AH, Eberhard J. Evaluating depressive symptoms in mania: a naturalistic study of patients with bipolar disorder. Neuropsychiatr Dis Treat. 2015;11:1137-1143.

11. Valtonen HM, Suominen K, Haukka J, et al. Differences in incidence of suicide attempts during phases of bipolar I and II disorders. Bipolar Disord. 2008;10(5):588-596.

12. Fountoulakis KN, Kasper S, Andreassen O, et al. Efficacy of pharmacotherapy in bipolar disorder: a report by the WPA section on pharmacopsychiatry. Eur Arch Psychiatry Clin Neurosci. 2012;262(suppl 1): $1-48$.

13. Podawiltz A. A review of current bipolar disorder treatment guidelines. J Clin Psychiatry. 2012;73(3):e12.

14. Cohn JB, Collins G, Ashbrook E, Wernicke JF. A comparison of fluoxetine imipramine and placebo in patients with bipolar depressive disorder. Int Clin Psychopharmacol. 1989;4(4):313-322.

15. Gijsman HJ, Geddes JR, Rendell JM, Nolen WA, Goodwin GM. Antidepressants for bipolar depression: a systematic review of randomized, controlled trials. Am J Psychiatry. 2004;161(9):1537-1547.

16. Yatham LN, Kennedy SH, Schaffer A, et al. Canadian network for mood and anxiety treatments (CANMAT) and International Society for bipolar disorders (ISBD) collaborative update of CANMAT guidelines for the management of patients with bipolar disorder: update 2009. Bipolar Disord. 2009;11(3):225-255.

17. Walpoth-Niederwanger M, Kemmler G, Grunze H, et al. Treatment patterns in inpatients with bipolar disorder at a psychiatric university hospital over a 9-year period: focus on mood stabilizers. Int Clin Psychopharmacol. 2012;27(5):256-266.

18. Zhang Y, Yang H, Yang S, et al. Antidepressants for bipolar disorder: a meta-analysis of randomized, double-blind, controlled trials. Neural Regen Res. 2013;8(31):2962-2974.

19. Sidor MM, Macqueen GM. Antidepressants for the acute treatment of bipolar depression: a systematic review and meta-analysis. $J$ Clin Psychiatry. 2011;72(2):156-167.

20. Angst J. Switch from depression to mania, or from mania to depression. J Psychopharmacol. 1987;1(1):13-19.

21. Serretti A, Lilli R, Smeraldi E. Pharmacogenetics in affective disorders. Eur J Pharmacol. 2002;438(3):117-128.

22. Truman CJ, Goldberg JF, Ghaemi SN, et al. Self-reported history of manic/hypomanic switch associated with antidepressant use: data from the systematic treatment enhancement program for bipolar disorder (STEP-BD). J Clin Psychiatry. 2007;68(10):1472-1479.

23. Post RM, Stoddard FJ, Gillin JC, et al. Alterations in motor activity, sleep, and biochemistry in a cycling manic-depressive patient. Arch Gen Psychiatry. 1977;34(4):470-477.

24. Bunney WE Jr, Murphy DL, Goodwin FK, Borge GF. The switch process from depression to mania: relationship to drugs which alter brain amines. Lancet. 1970;1(7655):1022-1027. 
25. Juckel G, Hegerl U, Mavrogiorgou P, et al. Clinical and biological findings in a case with 48-hour bipolar ultrarapid cycling before and during valproate treatment. J Clin Psychiatry. 2000;61(8):585-593.

26. Murphy DL, Brodie HK, Goodwin FK, Bunney WE Jr. Regular induction of hypomania by L-dopa in "bipolar" manic-depressive patients. Nature. 1971;229(5280):135-136.

27. Factor SA, Molho ES, Podskalny GD, Brown D. Parkinson's disease: drug-induced psychiatric states. Adv Neurol. 1995;65:115-138.

28. Kurita M, Nishino S, Numata Y, Okubo Y, Sato T. The noradrenaline metabolite MHPG is a candidate biomarker from the manic to the remission state in bipolar disorder I: a clinical naturalistic study. PLoS One. 2014;9(6):e100634.

29. Yoshimura R, Nakano Y, Hori H, Ikenouchi A, Ueda N, Nakamura J. Effect of risperidone on plasma catecholamine metabolites and brainderived neurotrophic factor in patients with bipolar disorders. Hum Psychopharmacol. 2006;21(7):433-438.

30. Bowers MB Jr, Swigar ME, Jatlow PI, Hoffman FJ. Plasma catecholamine metabolites and treatment response at neuroleptic steady state. Biol Psychiatry. 1989;25(6):734-738.

31. Drevets WC, Gautier C, Price JC, et al. Amphetamine-induced dopamine release in human ventral striatum correlates with euphoria. Biol Psychiatry. 2001;49(2):81-96.

32. Lu YY, Lin CH, Lane HY. Mania following ketamine abuse. Neuropsychiatr Dis Treat. 2016;12:237-239.

33. Li B, Liu ML, Wu XP, et al. Effects of ketamine exposure on dopamine concentrations and dopamine type 2 receptor mRNA expression in rat brain tissue. Int J Clin Exp Med. 2015;8(7):11181-11187.

34. Burris KD, Molski TF, Xu C, et al. Aripiprazole, a novel antipsychotic, is a high-affinity partial agonist at human dopamine D2 receptors. J Pharmacol Exp Ther. 2002;302(1):381-389.

35. Keck PE Jr, Calabrese JR, McQuade RD, et al; Aripiprazole Study Group. A randomized, double-blind, placebo-controlled 26-week trial of aripiprazole in recently manic patients with bipolar I disorder. J Clin Psychiatry. 2006;67(4):626-637.

36. Keck PE Jr, Calabrese JR, McIntyre RS, et al; Aripiprazole Study Group. Aripiprazole monotherapy for maintenance therapy in bipolar I disorder: a 100-week, double-blind study versus placebo. J Clin Psychiatry. 2007;68(10):1480-1491.

37. Thase ME, Jonas A, Khan A, et al. Aripiprazole monotherapy in nonpsychotic bipolar I depression: results of 2 randomized, placebo-controlled studies. J Clin Psychopharmacol. 2008;28(1):13-20.

38. Zumarraga M, Davila R, Basterreche N, et al. Catechol O-methyltransferase and monoamine oxidase A genotypes, and plasma catecholamine metabolites in bipolar and schizophrenic patients. Neurochem Int. 2010;56(6-7):774-779.

39. Barbosa IG, Rocha NP, Miranda AS, et al. Increased BDNF levels in long-term bipolar disorder patients. Rev Bras Psiquiatr. 2013;35(1): 67-69.
40. Barbosa IG, Huguet RB, Mendonca VA, et al. Increased plasma levels of brain-derived neurotrophic factor in patients with long-term bipolar disorder. Neurosci Lett. 2010;475(2):95-98.

41. Machado-Vieira R, Dietrich MO, Leke R, et al. Decreased plasma brain derived neurotrophic factor levels in unmedicated bipolar patients during manic episode. Biol Psychiatry. 2007;61(2):142-144.

42. Chen B, Dowlatshahi D, MacQueen GM, Wang JF, Young LT. Increased hippocampal BDNF immunoreactivity in subjects treated with antidepressant medication. Biol Psychiatry. 2001;50(4):260-265.

43. Balu DT, Hoshaw BA, Malberg JE, Rosenzweig-Lipson S, Schechter LE, Lucki I. Differential regulation of central BDNF protein levels by antidepressant and non-antidepressant drug treatments. Brain Res. 2008;1211:37-43.

44. Malhi GS, Tanious M, Das P, Berk M. The science and practice of lithium therapy. Aust N Z J Psychiatry. 2012;46(3):192-211.

45. Meyer JH, Ginovart N, Boovariwala A, et al. Elevated monoamine oxidase a levels in the brain: an explanation for the monoamine imbalance of major depression. Arch Gen Psychiatry. 2006;63(11):1209-1216.

46. Finberg JP. Update on the pharmacology of selective inhibitors of MAO-A and MAO-B: focus on modulation of CNS monoamine neurotransmitter release. Pharmacol Ther. 2014;143(2):133-152.

47. Edmondson DE, Binda C, Wang J, Upadhyay AK, Mattevi A. Molecular and mechanistic properties of the membrane-bound mitochondrial monoamine oxidases. Biochemistry. 2009;48(20):4220-4230.

48. Basavraj V, Nanjundappa GB, Chandra PS. Mirtazapine induced mania in a woman with major depression in the absence of features of bipolarity. Aust N Z J Psychiatry. 2011;45(10):901.

49. Gao K, Kemp DE, Ganocy SJ, et al. Treatment-emergent mania/ hypomania during antidepressant monotherapy in patients with rapid cycling bipolar disorder. Bipolar Disord. 2008;10(8):907-915.

50. Boerlin HL, Gitlin MJ, Zoellner LA, Hammen CL. Bipolar depression and antidepressant-induced mania: a naturalistic study. J Clin Psychiatry. 1998;59(7):374-379.

51. Bottlender R, RudolfD, Strauss A, Moller HJ. Mood-stabilisers reduce the risk of developing antidepressant-induced maniform states in acute treatment of bipolar I depressed patients. J Affect Disord. 2001;63(1-3):79-83.

52. Tatsumi M, Groshan K, Blakely RD, Richelson E. Pharmacological profile of antidepressants and related compounds at human monoamine transporters. Eur J Pharmacol. 1997;340(2-3):249-258.

53. McElroy SL, Weisler RH, Chang W, et al; EMBOLDEN II (Trial D1447C00134) Investigators. A double-blind, placebo-controlled study of quetiapine and paroxetine as monotherapy in adults with bipolar depression (EMBOLDEN II). J Clin Psychiatry. 2010;71(2): $163-174$.
Neuropsychiatric Disease and Treatment

\section{Publish your work in this journal}

Neuropsychiatric Disease and Treatment is an international, peerreviewed journal of clinical therapeutics and pharmacology focusing on concise rapid reporting of clinical or pre-clinical studies on a range of neuropsychiatric and neurological disorders. This journal is indexed on PubMed Central, the 'PsycINFO' database and CAS,
Dovepress

and is the official journal of The International Neuropsychiatric Association (INA). The manuscript management system is completely online and includes a very quick and fair peer-review system, which is all easy to use. Visit http://www.dovepress.com/testimonials.php to read real quotes from published authors. 